\title{
Corrigendum: Calvin on slavery: Providence and social ethics in the 16th century
}

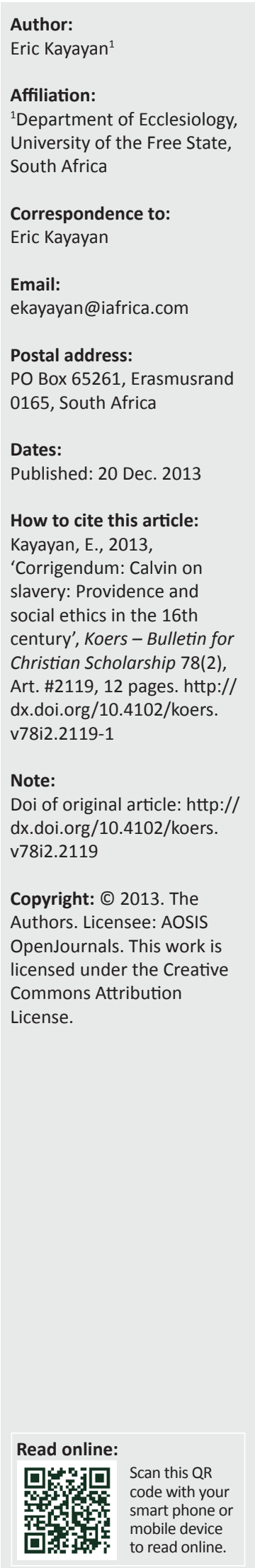

On the bottom of page 4 of 12 , in footnote 9 , reference is made to the dates '(1561-1556)', the correct dates should be: '(1561-1566).'

On page 12 of 12, in the last paragraph of the left column, the citation in parenthesis '(CO 24, 700-702 cf. the end of note 18)' should read: '(CO 24, 700-702 cf. the end of note 15).' 